\title{
The effect of experimental manipulation on cooperative behavior in a chicken game'
}

VELLO SERMAT AND ROBERT P. GREGOVICH

UNIVERSITI OF OREGON

Forty male and 40 female undergraduates participated in a mixed-motive game. For the first 50 trials, a simulated "other player" used a tit-for-tat strategy which reciprocated the S's choices with a one-trial lag. Ss who received the same choice from the "other" on the first trial became significantly more cooperative in the next 50 trials than Ss who received a different choice. A second phase explored some experimental treatments which were designed to change the degree of cooperation or competition shown by the $S$, and demonstrated significant effects in the predicted direction.

A number of investigations have failed to produce any marked effect on S's game behavior by systematically varying information about the other player's behavior (Gallo \& McClintock, 1965; Sermat, 1964). The present study investigated two problems: (1) the relationship of S's first choice and the first choice of a simulated "other" to S's subsequent game behavior, and (2) the effectiveness of a flexible treatment program, in which an experienced experimenter assumes the role of the other player, to produce changes in the strategy employed by $S$.

\section{Method}

The Ss were 40 males and 40 females from introductory psychology courses at the University of Oregon. Four Ss of the same sex, separated by opaque screens, participated simultaneously. In front of each $\mathrm{S}$ was a panel displaying the payoff matrix and two black and two red pushbuttons, arranged as shown in Fig. 1. This type of game yields the lowest payoff when both participants choose the competitive (red) alternative, and is known as the game of "Chicken." Each $\mathrm{S}$ was told that he would be paired with one of the other three individuals present, that their choices would jointly determine their payoffs as shown in the matrix, and that each $\mathrm{S}$ was to attempt to make as many points as possible for himself.

Three males and two females served as experimenters. In each experimental session, two E's were present, but only one was seen by the Ss. Each $E$ served as the visible experimenter for 8 male and 8 female Ss. During the experiment, each of the two E's present gave payoff information to two of the Ss, as follows.

During trials 1-50, the alleged "other player" made whatever choice $S$ had made on the immediately preceding trial (the 'tit-for-tat' strategy), except for the first trial, where the "other's" choice was determined by tossing a coin. At the end of the first 50-

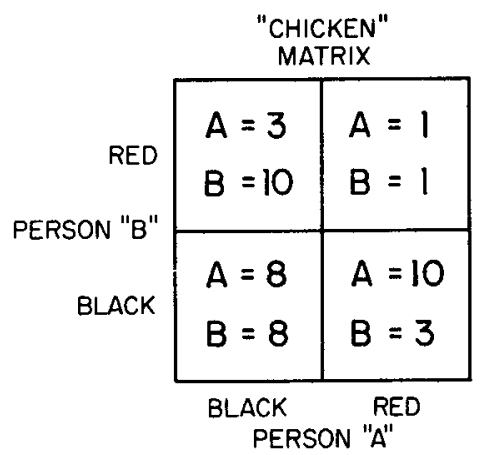

Fig. 1. The payoff matrix.

trial session, E classified as "cooperators" those Ss who had made 4 or fewer red choices in the last 20 trials, and as "competitors" those Ss who had made 5 or more red choices.

For trials 51-100, E continued to treat the "cooperating"' Ss with a general tit-for-tat strategy, except that the $S$ was given two more red choices from the "other" in each 10-trial block than would have been required by the $S$ 's own preceding choice sequence. If the $S$ had been classified as a "competitor," $E$ was required to use whatever strategy he judged as ap-

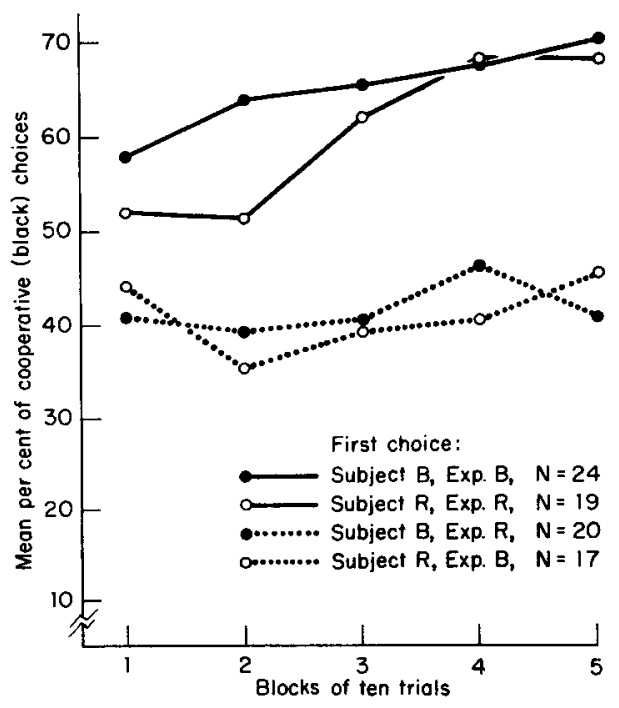

Fig. 2. Mean per cent of cooperative choices by subjects who received either the same (BB, RR) or different $(B R, R B)$ choice on first trial. 
propriate in order to make the $\mathrm{S}$ more cooperative. After trial 100, Ss were once more classified as "cooperators" or "competitors" on the basis of their performance in trials 81-100, and the same rules for treatment were used.

\section{Results}

Trials 1-50. It is apparent from Fig。 2 that Ss whose first choice coincided with that of the simulated "other player" made a higher number of cooperative choices than did Ss whose first move differed from that of the simulated "other." Among same-choice Ss, 18 made 50 per cent or fewer black choices on trials 1-50 and 25 made more than 50 per cent black choices; for different-choice Ss the corresponding frequencies were 29 and 8 respectively. The resulting Chi-square of 11.1 is significant at the .005 level.

Trials 51-150. Figure 3 shows the treatment effects on cooperation during the second phase of the experiment. Of $67 \mathrm{Ss}$ who made fewer than 80 per cent of cooperative choices in trials $81-100$ and were subsequently given individually designed treatments to make them more cooperative, 45 became more cooperative, 17 became less cooperative, and five did not change (sign test $\mathrm{p}<.005$ ). Of the $13 \mathrm{Ss}$ who made 80 per cent or more cooperative choices in trials 81 100 and who were subsequently given at least 20 per cent competitive choices by the "other," 10 became more competitive, 2 more cooperative, and one did not change (sign test $\mathrm{p}<.025$ ).

\section{Discussion}

The results show that whether the "other's" choice is the same or different from $\mathrm{S}$, is crucial. Mutual cooperation on the first trial rewarded the $S$ with a relatively high payoff of 8 points, while mutual competition punished him with the lowest possible payoff of 1 point. Both of these outcomes are likely to strengthen the tendency to choose cooperatively. On the other hand, different choices are likely to strengthen the competitive tendency. When the $\mathrm{S}$ chose red while the "other" chose black, $\mathrm{S}$ was rewarded for competition with both the highest payoff (10 points) and a differential gain over the other player. When the $S$ chose black while the "other" chose red, Swas punished for cooperation with both a low payoff (3 points) and a differential loss.

In previous research (Sermat, 1964; Sermat, 1966), fixed treatments, uniformly administered to all Ss throughout the experiment, had only limited success in

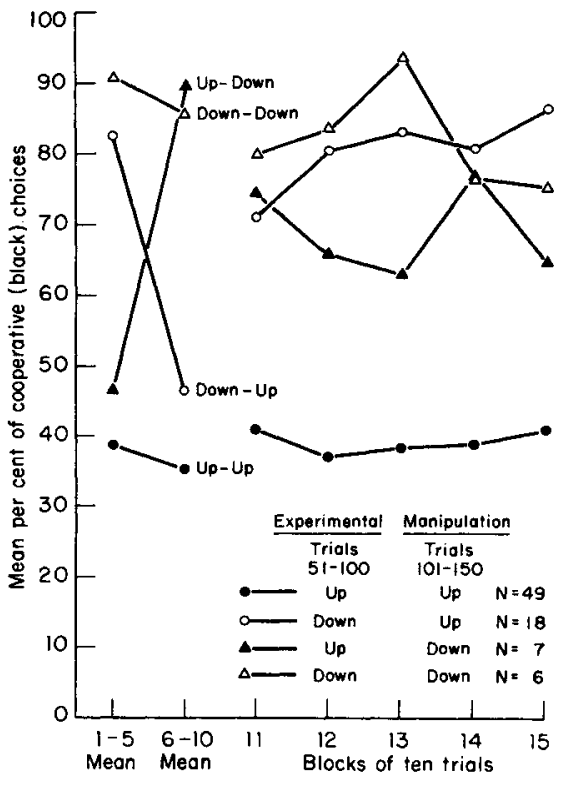

Fig. 3. Mean per cent of cooperative choices by subjects who were manipulated to become either more cooperative ("up") or more competitive ("down").

inducing cooperation. For this reason, "competitive" Ss were given a flexible treatment, adapted to the S's own behavior, with the hope of increasing cooperative behavior. A significant increase in cooperation was found. However, Fig. 3 reveals that while a minority of competitive Ss became highly cooperative during trials 51-100, the large majority of competitive Ss became only slightly more cooperative as a result of 100 trials of experimental manipulation. On the other hand, even the small amount of competitive exploitation used in the present study reduced cooperative behavior in the majority of cooperative Ss.

\section{References}

Gallo, P. S., Jr., \& McClintock, C. G. Cooperative and competitive behavior in mixed motive games. J. conflict Resolut, 1965 , 9, 68-78.

Sermat, V. Cooperative behavior in a mixed-motive game. $J$. soc. Psychol, 1964, 62, 217-239.

Sermat, V. Effects of preceding game experience and contingent treatment on cooperative behavior in a mixed-motive game. Unpublished manuscript, University of Oregon, 1966.

Note

1. This research was supported by NSF Grant GS-583 to V. Sermat. 